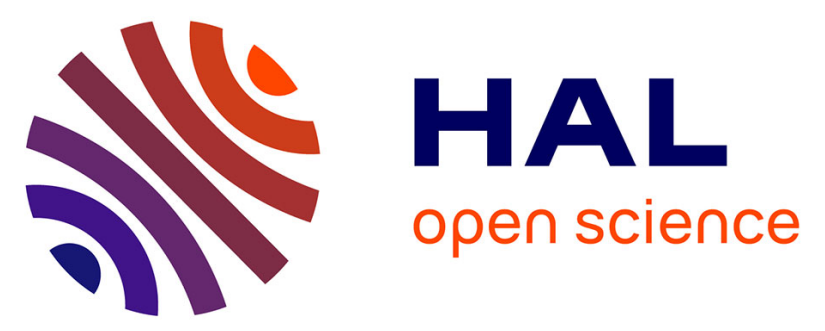

\title{
Insight into the Ozone-Assisted Low-Temperature Combustion of Dimethyl Ether by Means of Stabilized Cool Flames
}

\author{
Thomas Panaget, Nabil Mokrani, Sébastien Batut, Amaury Lahccen, Yann \\ Fenard, Laure Pillier, Guillaume Vanhove
}

\section{To cite this version:}

Thomas Panaget, Nabil Mokrani, Sébastien Batut, Amaury Lahccen, Yann Fenard, et al.. Insight into the Ozone-Assisted Low-Temperature Combustion of Dimethyl Ether by Means of Stabilized Cool Flames. Journal of Physical Chemistry A, 2021, 10.1021/acs.jpca.1c05583 . hal-03386034

\section{HAL Id: hal-03386034 https://hal.science/hal-03386034}

Submitted on 19 Oct 2021

HAL is a multi-disciplinary open access archive for the deposit and dissemination of scientific research documents, whether they are published or not. The documents may come from teaching and research institutions in France or abroad, or from public or private research centers.
L'archive ouverte pluridisciplinaire HAL, est destinée au dépôt et à la diffusion de documents scientifiques de niveau recherche, publiés ou non, émanant des établissements d'enseignement et de recherche français ou étrangers, des laboratoires publics ou privés. 


\section{Insight into the Ozone-Assisted Low-Temperature Combustion of Dimethyl Ether by Means of Stabilized Cool Flames}

Thomas Panaget, Nabil Mokrani, Sébastien Batut, Amaury Lahccen, Yann Fenard, Laure Pillier, Guillaume Vanhove*

Univ. Lille, CNRS, UMR 8522 - PC2A - Physicochimie des Processus de Combustion et de

1'Atmosphère, F-59000 Lille, France

KEYWORDS

Low-temperature combustion; Cool flame; Ozone; Formaldehyde PLIF; Kinetic modeling;

*corresponding author

guillaume.vanhove@univ-lille.fr 


\section{ABSTRACT}

The low-temperature combustion kinetics of dimethyl ether (DME) were studied by means of stabilized cool flames in a heated stagnation plate burner configuration, using ozone-seeded premixed flows of $\mathrm{DME} / \mathrm{O}_{2}$. Direct imaging of $\mathrm{CH}_{2} \mathrm{O}^{*}$ chemiluminescence and Laser Induced Fluorescence of $\mathrm{CH}_{2} \mathrm{O}$ were used to determine flame front positions in a wide range of lean and ultra-lean equivalence ratios and ozone concentrations, for two strain rates. Temperature and species mole fraction profiles along the flame were measured coupling thermocouples, gas chromatography, micro-chromatography and quadrupole mass spectrometry analysis. A new kinetic model was built on the basis of the Aramco 1.3 model, coupled with a validated submechanism of $\mathrm{O}_{3}$ chemistry, and was updated to improve the agreement with the obtained experimental results and experimental data available in the literature. Main results show the efficiency of the tested model to predict the flame front position and temperature in every tested condition, as well as the importance of reactions typical of atmospheric chemistry in the prediction of cool flame occurrence. The agreement on the fuel and major products is overall good, except for methanol, highlighting some missing kinetic pathways for the $\mathrm{DME} / \mathrm{O}_{2} / \mathrm{O}_{3}$ system, possibly linked to the direct addition of atomic oxygen on the fuel radical, modifying the products distribution after the cool flame.

\section{Introduction}

In the current context - where a growing energy demand meets decreasing fossil fuel stocks and a need to decrease greenhouse gases, nitrogen oxides and soot emissions - alternative energy carriers are seen as a sustainable solution for combustion applications. These last years, oxygenated biofuels and e-fuels have attracted attention because of their ability to reduce pollutant emissions on the full well-to-wheel cycle ${ }^{1}$. Especially Poly(oxymethylene) dimethyl ethers (POMDMEs), also called Oxymethylene ethers (OMEs), with the general structure $\mathrm{CH}_{3}$ $\mathrm{O}-\left(\mathrm{CH}_{2}-\mathrm{O}\right)_{\mathrm{n}}-\mathrm{CH}_{3}$, have the potential to reduce soot production during combustion processes due to their high oxygen content and the absence of $\mathrm{C}-\mathrm{C}$ bond ${ }^{2,3}$ in the fuel structure. Their production also presents great interest in reducing global carbon footprint: The smallest OME, $\mathrm{OME}_{0}$ or dimethyl ether (DME), can be directly produced from recycled $\mathrm{CO}_{2}{ }^{4,5}$. Larger OMEs can also be produced from methanol and formaldehyde ${ }^{6}$ with a competitive price compared to conventional diesel fuel production ${ }^{7}$, reinforcing their position as diesel fuel alternative.

In parallel, recent research has been focused on new combustion concepts to reconcile high thermal efficiency and low pollutant emissions. Technologies such as HCCI (Homogeneous

Charge Compression Ignition) ${ }^{8}$ or SACI (Spark Assisted Compression Ignition) ${ }^{9}$ could help reach these goals inside internal combustion engines. These concepts depend strongly on Low 
Temperature Combustion (LTC) kinetics ${ }^{10}$, governing the auto-ignition of the fuel. They result in a phenomenon, called cool flame, which is generally studied in Jet-Stirred Reactors (JSR) ${ }^{11}$ or Rapid Compression Machines (RCM) ${ }^{12}$. However, quantification of the heat release is typically difficult using such devices, as JSR operate in highly-diluted and isothermal conditions, and RCM use creviced pistons to mitigate fluid motion after compression, allowing part of the mixture to transfer to the crevice during the first-stage ignition, and therefore reducing the relevant pressure increase. Facilities in which the study of the low temperature combustion of fuels can be operated in permanent, non-diluted regime, such as burner-stabilized cool flames, are therefore useful to quantify the heat release of cool flames, which is in turn correlated to second-stage ignition in $\mathrm{RCMs}^{13,14}$.

First observations of cool flames were achieved two centuries ago ${ }^{15}$ by igniting gaseous diethyl ether over a heated platinum wire. Few studies on stabilized double flames of $n$-butane were realized some decades ago ${ }^{16,17}$, but this research field gained a renewed interest in the context of plasma-assisted ignition ${ }^{18}$ and ozone-assisted ignition ${ }^{19}$. To this day, studies have been performed to stabilize cool flames in different configurations and for different fuels, however we will mainly focus here on studies using dimethyl ether as the fuel. Lee et al. ${ }^{20}$ studied wallstabilized premixed $\mathrm{DME} / \mathrm{O}_{2}$ cool flames using a heated plate at $700 \mathrm{~K}$, observing the formaldehyde distribution by Planar Laser Induced Fluorescence $\left(\mathrm{CH}_{2} \mathrm{O}-\mathrm{PLIF}\right)$. Reuter et al. studied $\mathrm{DME} / \mathrm{O}_{2} / \mathrm{O}_{3}{ }^{21}$ and $\mathrm{DME} / \mathrm{CH}_{4} / \mathrm{O}_{2} / \mathrm{O}_{3}{ }^{22}$ premixed cool flames, partially premixed $\mathrm{DME} / \mathrm{O}_{2} / \mathrm{O}_{3}$ cool flames ${ }^{23}$ in a counterflow burner working at atmospheric pressure, with an ozone concentration in the oxidizer ranging from 2.9 to $3.7 \%$. Their studies were mainly based on the comparison of hot and cool flames extinction strain rates in a wide range of conditions. Hajilou et al. studied premixed $\mathrm{DME} / \mathrm{O}_{2} / \mathrm{O}_{3}$ cool flames in a Hencken burner working at low pressure $^{24}$, with an ozone concentration in the oxidizer of $6.1 \%$, reporting for the first time an estimation of the propagation speed of the cool flame. Zhao et al. succeeded at stabilizing a cool flame of DME $/ \mathrm{O}_{2}$ without $\mathrm{O}_{3}$ addition, working in a counterflow burner, but in a rich mixture configuration of $\phi=1.5^{25}$. Planar Laser Induced Fluorescence of formaldehyde ${ }^{26}\left(\mathrm{CH}_{2} \mathrm{O}-\mathrm{PLIF}\right)$ proved to be an efficient tool in characterizing such flames, allowing a clear distinction between cool and hot flames. These studies highlighted the impact of ozone in promoting the low temperature combustion of the fuel in ultra-lean conditions, as also observed at lower concentrations in Jet-Stirred Reactor ${ }^{27}$ and Flow Reactor ${ }^{28}$ or Rapid Compression Machine ${ }^{29}$ configurations, confirming its potential for the control or enhancement of combustion in ultralean conditions.

The aim of this study is to present a newly developed burner dedicated to the investigation of such flames, resulting from the low temperature oxidation of the fuel. Cool flames were stabilized by ozone-seeding a DME $/ \mathrm{O}_{2}$ flow under a heated plate. This setup allowed the stabilization of lean and ultra-lean cool flames, with equivalence ratios ranging from 0.2 to 0.5 , and with ozone mole fractions in the mixture varying from $1.2 \%$ to $2.4 \%$. $\mathrm{CH}_{2} \mathrm{O}_{-}$ Chemiluminescence and $\mathrm{CH}_{2} \mathrm{O}$-PLIF permitted the measurement of flame front positions in a wide range of experimental conditions. Temperature and major stable species profiles were 
established for two different conditions, i.e. at equivalence ratio of 0.3 and 0.5 . These experimental results were used as validation target for a kinetic model developed on the basis of the Aramco $1.3^{30}$ kinetic model, which was further updated to include pathways missing from the original model.

\section{Experimental method}

The burner developed and used for this study is presented in Figure 1. It consists of a stainlesssteel body, with a coaxial nozzle of an inner diameter of $10 \mathrm{~mm}$ for the $\mathrm{DME} / \mathrm{O}_{2} / \mathrm{O}_{3}$ mixture. The mixture was injected through 4 orthogonal inlets and flows through a steel porous disc, shown as a yellow disc in Figure 1, before entering the convergent section of the burner. This geometry was established following the work of Rolon et al. ${ }^{31}$, ensuring laminar and uniform flow at the burner exit. A neat $\mathrm{N}_{2}$ co-flow was injected via the co-axial nozzle, also equipped with a stainless steel porous section with a $20 \mathrm{~mm}$ internal diameter, to isolate the flame from external perturbations. The burner body was kept at $300 \mathrm{~K}$ by cool water circulation. Experiments were operated at atmospheric pressure.

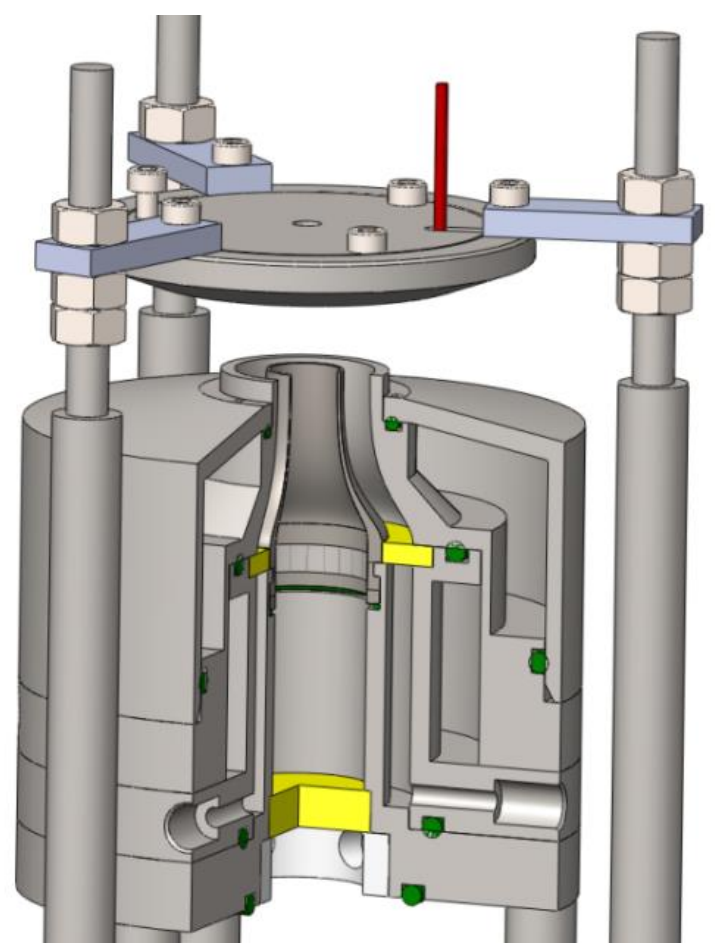

Figure 1. Stagnation plate burner setup used in this study.

A cylindrical heated plate, with a diameter of $65 \mathrm{~mm}$ and a thickness of $8 \mathrm{~mm}$, was placed at $13 \mathrm{~mm}$ above the burner nozzle, with a strictly parallel geometry, and was heated at $600 \pm 0.1 \mathrm{~K}$. Gas flow rates were controlled by Bronkhorst mass flow controllers. The oxygen flow was 
directed to a BMT $803 \mathrm{~N}$ ozone generator, the ozone mole fraction in the oxygen flow being measured at the entrance of the burner with a Teledyne API 452 ozone analyzer. The relative uncertainty on the ozone measurement is $\pm 0.02 \%$ on the reported values.

As cool flames are characterized by very low light emission, mostly due to the chemiluminescence of excited formaldehyde $\mathrm{CH}_{2} \mathrm{O}^{*}$, they require adaptation to be observed with the naked eye and therefore the cool flame emission was recorded using an ICCD Princeton PIMAX3 camera. A bandpass filter (396-450 nm) was used to suppress stray light from other species. The obtained images were further treated with three-point Abel inversion ${ }^{32}$ to extract axial $\mathrm{CH}_{2} \mathrm{O}^{*}$ profiles and determine cool flame positions, defined as the position above the burner at which the emission of $\mathrm{CH}_{2} \mathrm{O} *$ is maximal.

$\mathrm{CH}_{2} \mathrm{O}$-PLIF was used to measure the 2D spatial distribution of ground-level formaldehyde above the burner, and permitted the measurement of the flame front position through another technique. Formaldehyde excitation was performed at $355 \mathrm{~nm}$ using the third harmonic of a Qswitched Quantel Brilliant B Nd:YAG laser. The laser beam was converted into a laser sheet of $300 \mu \mathrm{m}$ thickness and $\sim 12.2 \mathrm{~mm}$ height. The laser pulse duration was $15 \mathrm{~ns}$ at a $20 \mathrm{~Hz}$ repetition rate. In this configuration, the laser delivered a $50 \mathrm{~mJ} /$ pulse energy intensity. The vertical energy distribution was measured by collecting the Raman signal from a quartz cell filled with ultrapure water, and was used to correct the PLIF signal after acquisition. Semi-automated treatment of the PLIF images was used to infer cool flame positions, which were then defined in the experiments and simulations as the position of the maximum of the derivative of the $\mathrm{CH}_{2} \mathrm{O}$ signal. The signal was averaged on 40 pixels centered on the burner axis. Details on the comparison between these two techniques $\left(\mathrm{CH}_{2} \mathrm{O}\right.$-chemiluminescence and $\mathrm{CH}_{2} \mathrm{O}$-PLIF) will be discussed later. The uncertainty on the cool flame position with the PLIF method was estimated to $\pm 150 \mu \mathrm{m}$, while the uncertainty on the same measurement with the chemiluminescence method can be roughly estimated to $\pm 250 \mu \mathrm{m}$.

Temperature profiles inside the flame were measured with a $250 \mu \mathrm{m}$ diameter type $\mathrm{K}$ thermocouple. Measurements were performed from the side, the tip of the thermocouple lying along the axis of the burner. Repeatability and the absence of catalytic effects due to the presence of the thermocouple were ensured by performing two runs, one starting the measurement from the burner towards the plate and one in the opposite direction, yielding nearly identical temperature profiles, as demonstrated in the Supplementary Material. The global uncertainty on the flame temperature was estimated to $\pm 25 \mathrm{~K}$, corresponding to the maximum observed deviation between the two runs described above. The uncertainty on the measurement position was considered equal to the thermocouple radius, $\pm 125 \mu \mathrm{m}$, as the position of the thermocouple was periodically verified using a scope. Radiative heat losses were neglected in this study since the experimental and simulated maximal cool flame temperatures typically do not exceed $900 \mathrm{~K}$, which is below the frequently accepted limit of $1000 \mathrm{~K}$ for such an assumption ${ }^{33}$. Since perturbation of the flame front can be expected from such an intrusive measurement, temperature profiles were performed with different thermocouples with diameters ranging from $250 \mu \mathrm{m}$ to 1 $\mathrm{mm}$. It was observed that while the temperature gradient was strongly affected at the largest 
thermocouple diameters, the maximum temperature downstream from the flame front was identical (within the experimental uncertainty) whatever the thermocouple diameter, as demonstrated in the Figure S1 in the Supplementary Material. The primary objective of these measurements was the determination of the maximum temperatures after the flame front, and the reported post-flame temperatures can therefore be trusted as not being affected by the intrusion of the thermocouple into the gases.

Major species mole fraction profiles were established with a conjunction of micro-Gas Chromatography ( $\mu \mathrm{GC}$ ), Gas Chromatography (GC) and Quadrupole Mass Spectrometry (QMS) techniques. Sampling was operated using a $250 \mu \mathrm{m}$ external diameter, $150 \mu \mathrm{m}$ internal diameter capillary. The ozone mole fractions were measured with an Omnistar GSD 301 O2 Pfeiffer Vacuum mass spectrometer, using a quadrupole mass analyser. Calibration was performed using $\mathrm{O}_{2} / \mathrm{O}_{3}$ mixtures using the same sampling procedure and on the same day as the flame experiments. The measurement of DME, $\mathrm{CH}_{2} \mathrm{O}, \mathrm{CO}_{2}, \mathrm{CH}_{3} \mathrm{OH}$ and $\mathrm{CH}_{3} \mathrm{OCHO}$ mole fractions was performed using an Agilent $490 \mu \mathrm{GC}$, equipped with a HP-PLOT U PT column and a TCD detector. The signal from $\mathrm{DME}$ was calibrated using $\mathrm{DME} / \mathrm{O}_{2}$ mixtures directly sampled at the burner exit. This method was initially validated by comparing the calibration factor obtained using this method with the one obtained from in-house prepared mixtures of $\mathrm{DME} . \mathrm{CO}_{2}$, $\mathrm{CH}_{3} \mathrm{OH}, \mathrm{CH}_{2} \mathrm{O}$ and $\mathrm{CH}_{3} \mathrm{OCHO}$ signals were calibrated using in-house prepared gas mixtures. Finally, CO mole fractions were measured with an Agilent $6890 \mathrm{GC}$, the permanent gases being separated on a CP-Molsieve 5A column and analyzed via TCD, and calibration being performed using a standard mixture. The relative uncertainty on species mole fraction measurements was estimated to $\pm 5 \%$ for DME, $\mathrm{CO}_{2}$ and $\mathrm{CH}_{3} \mathrm{OCHO}, \pm 10 \%$ for $\mathrm{O}_{3}, \mathrm{CH}_{2} \mathrm{O}$ and $\mathrm{CH}_{3} \mathrm{OH}$, and $\pm 20 \%$ for $\mathrm{CO}$. The carbon balance was evaluated, and yielded maximal deviation of $\pm 3 \%$ in the postflame region.

\section{Computational methods}

The Aramco 1.3 mechanism $^{30}$ coupled with the ozone submechanism from Foucher et al. ${ }^{34}$ was used to simulate the experimental results, resulting in a 254 species mechanism, including 1559 elementary reactions. The choice of version 1.3 of AramcoMech was motivated by an initial comparison of the performance of all published versions of this mechanism, demonstrating superior performance of this version in the prediction of cool flame occurrence and stabilization in comparison with later ones. In the light of the remaining discrepancies observed between the experimental and calculated intermediate species mole fractions, the mechanism was further updated. The modified or added reactions to the mechanism are summarized in Table 1. Details about the reasons behind such modifications will be discussed in the section dedicated to the results and discussion. The modified model was then tested against data from the literature to ensure its validity, showing similar to better performance against the validation targets, most notably in the low-temperature range, as demonstrated in the Figures S2, S3 and S4 of the 
Supplementary Material. Burning velocities were calculated using LOGEsoft ${ }^{35}$, and ignition delay times were calculated using a constant volume adiabatic reactor with Cantera ${ }^{36}$.

Table 1. Modifications operated on the Aramco $1.3\left(+\mathrm{O}_{3}\right.$ submechanism) model.

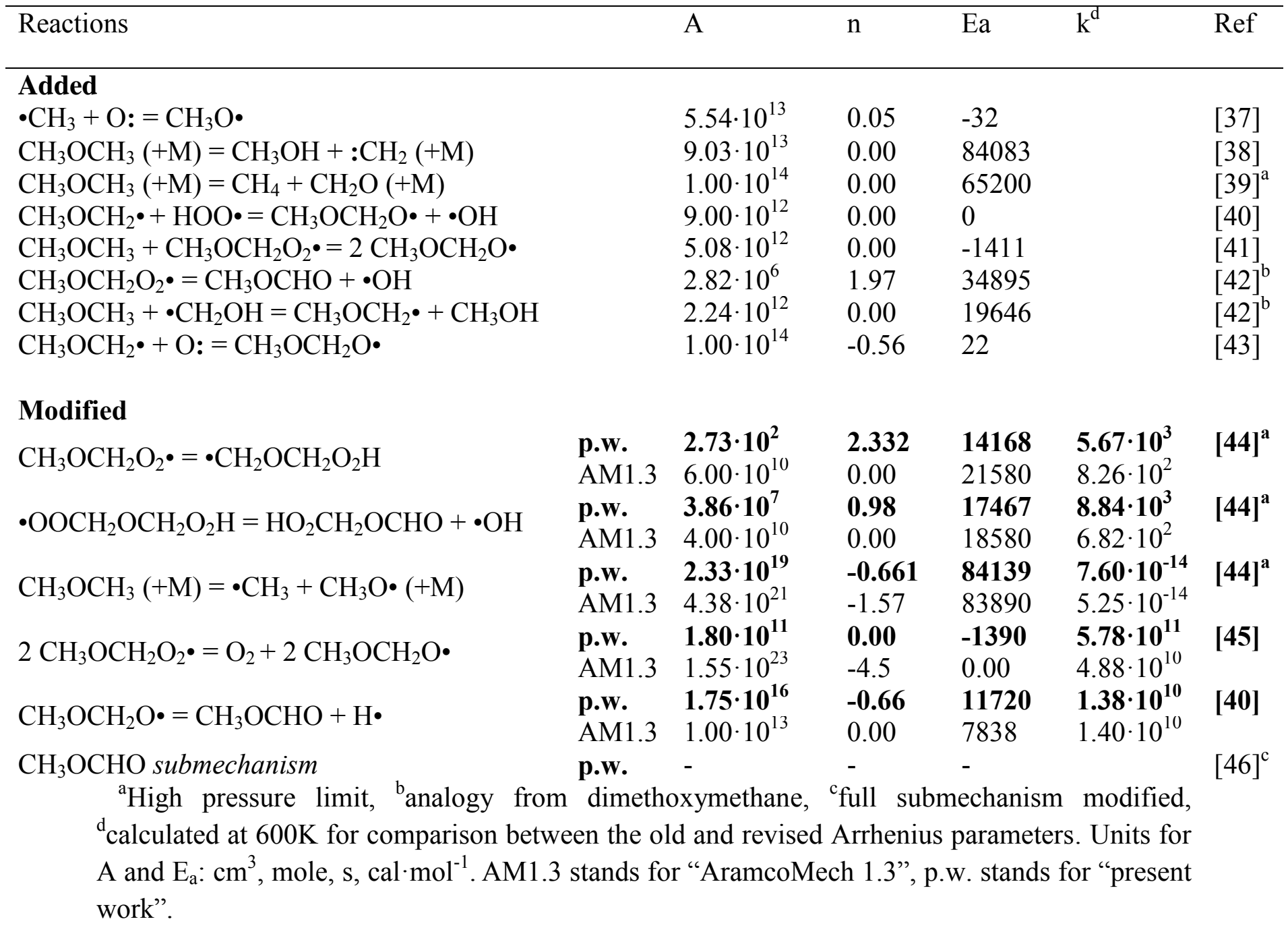

All flames were simulated with multicomponent transport using the impinging jet reactor class from Cantera ${ }^{36}$. In order to ensure the initiation of a cool flame in the simulations, the heated plate temperature was initially set to $700 \mathrm{~K}$, then progressively reduced in cases where a 'hot' flame condition was predicted, and finally set at the experimental value of $600 \mathrm{~K}$ before grid refinement. Cases of hot flames in the simulations were identified by maximal flame temperatures greater than $1000 \mathrm{~K}$. It should be stressed that since one of the purposes of this work is to enable a correct prediction of the heat release during the cool flame event, the measured temperature profiles were not used as input for the simulations, and the energy equation was solved during the computation. 
Lefkowitz et al. ${ }^{47}$ compared PLIF and probe measurement of acetone in a diffusion flame, and showed that the effect of the probe on the spatial distribution of the species could not be

neglected. Similarly, Lamoureux et al. ${ }^{48}$ conducted measurements of NO by LIF and in-situ probe sampling in a methane premixed flame, and observed a discrepancy in the species profiles between both techniques. The influence of the probe sampling on the species profiles could be important in our case, as ozone is known to be a species that can quickly decompose at temperatures greater than $400 \mathrm{~K}^{27,28}$. In order to evaluate the possibility of reactivity inside the sampling capillary, especially in the ozone-rich samples, additional simulations were performed, and will be referred to as 'facility effect' simulations later in this manuscript. For these simulations, a bidimensional temperature map of the flame was acquired using the same thermocouple as described in the experimental section, an example of such a map being presented in the Figure S5 in the Supplementary Material. For selected heights above the burner, the capillary was modeled as a plug-flow reactor (PFR) with an imposed temperature profile corresponding to the radial distribution of temperature inferred from the bidimensional temperature map, and inlet conditions corresponding to those calculated using the impinging jet approach described above. The flow rate inside the PFR was calculated at each height above the burner using the correlation given for a turbulent flow inside the capillary given in Wißdorf et $a l{ }^{49}$.

Brute-force sensitivity analyses were performed on the cool flame delay, i.e. the first stage ignition delay, and the sensitivity coefficient on the reaction $i, S_{i}$, was calculated as follows: $S_{i}=$ $\ln \left(\tau_{i}^{+} / \tau_{i}^{-}\right) / \ln (2 / 0.5) . \tau_{i}^{+}$represents the first stage ignition delay time when the pre-exponential of the reaction $i$ has been multiplied by a factor of two, and $\tau_{i}^{-}$represents the first stage ignition delay time when the pre-exponential of the reaction $i$ has been divided by a factor of two. A positive value of $S_{i}$ indicates an inhibiting effect of the reaction on the reactivity at a given temperature, and vice versa.

\section{Results and discussion}

Figure 2 summarizes the stability limits of experimental cool flames observed for two strain rates, 40 and $50 \mathrm{~s}^{-1}$. It is important to note that for the lowest equivalence ratio at each strain rate, the flashback could not be reached because the ozone production range of the generator was exceeded. The reported strain rates are calculated as the ratio between the flow velocity and the burner-plate distance. 


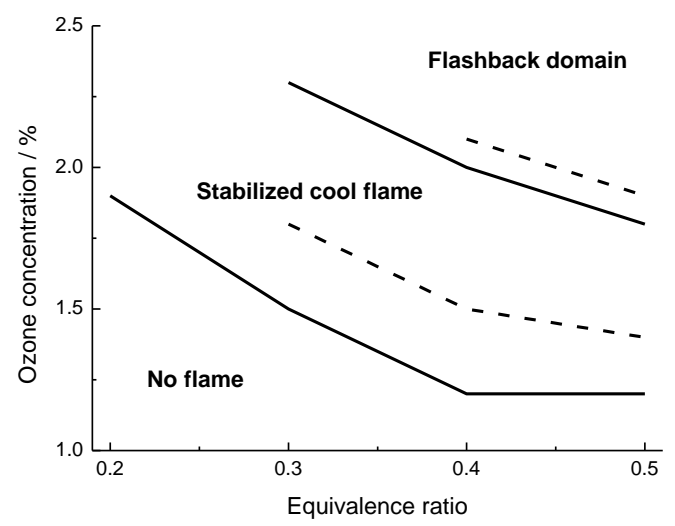

Figure 2. Stabilization map. Stability limits are represented by continuous lines at $40 \mathrm{~s}^{-1}$, and dashed lines at $50 \mathrm{~s}^{-1}$.

\section{$\mathrm{CH}_{2} \mathrm{O}$-PLIF \& $\mathrm{CH}_{2} \mathrm{O}$-Chemiluminescence}

Figure 3 shows representative raw images of excited formaldehyde chemiluminescence and stable formaldehyde fluorescence of a single flame stabilized in the burner.
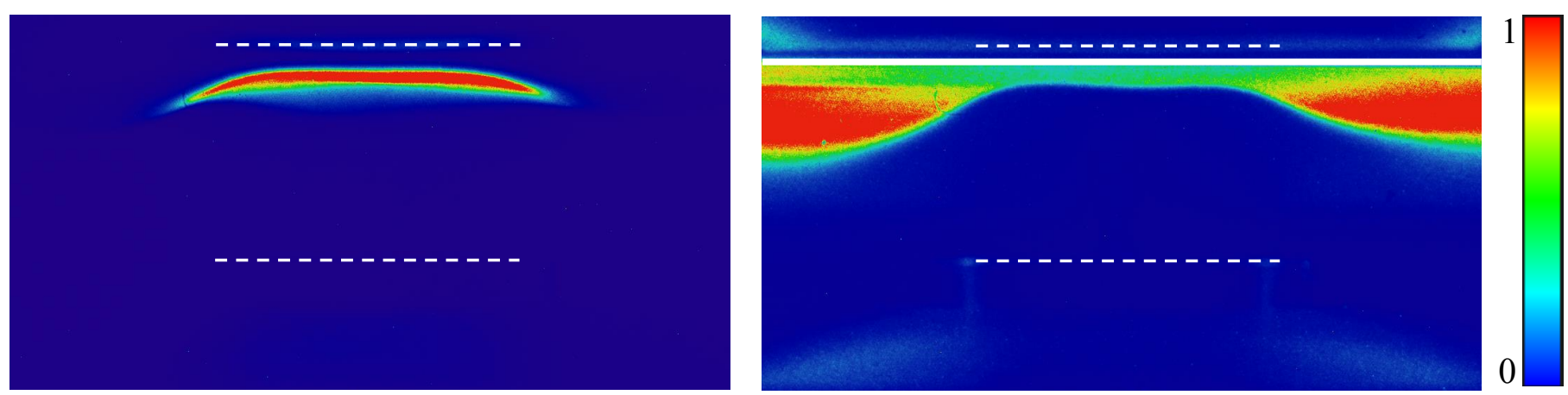

Figure 3. Raw $\mathrm{CH}_{2} \mathrm{O}^{*}$ chemiluminescence (left) and $\mathrm{CH}_{2} \mathrm{O}-\mathrm{PLIF}$ (right). $\alpha=40 \mathrm{~s}^{-1}, \phi=0.4, \mathrm{x}_{\mathrm{O} 3}$ $=1.6 \%$. The dashed lines represent the burner (bottom) and plate (top) positions, the solid line represents the top of the laser sheet. The color bar on the right indicates the relative intensity of each image, between 0 and 1 .

Formaldehyde is formed inside the flame front, and is present all the way to the heating plate, as expected in a cool flame case, as it is a stable oxidation product in this temperature range. In 'hot' or 'warm' flame cases, formaldehyde would indeed be fully converted in the flame front as a combustion intermediate. On the contrary, excited $\mathrm{CH}_{2} \mathrm{O}^{*}$ is formed in the flame front but quickly transitions to its ground-state, permitting another visualization of the flame front. Figure 3 shows that both techniques evidence a flat and axisymmetric flame front along a significant distance from the burner axis. This allows precise flame front position determination using the procedures described in the experimental section. Figure 4 shows a comparison of the extracted axial profiles as a function of the Height Above Burner (HAB) for both techniques. It demonstrates that the position for the maximum of the $\mathrm{CH}_{2} \mathrm{O}^{*}$ profile is close to the one of the 
maximum derivative of the $\mathrm{CH}_{2} \mathrm{O}$ LIF signal, demonstrating that both techniques will yield similar flame front positions. However, uncertainties associated to the Abel inversion result in a slightly larger uncertainty using the chemiluminescence approach. This uncertainty can be roughly estimated to $\pm 250 \mu \mathrm{m}$, in comparison to the $\pm 150 \mu \mathrm{m}$ associated to the PLIF measurement, that depend mostly on the resolution of the ICCD camera. The $\mathrm{CH}_{2} \mathrm{O}-\mathrm{PLIF}$ method was therefore used for all the flame positions reported in this study.

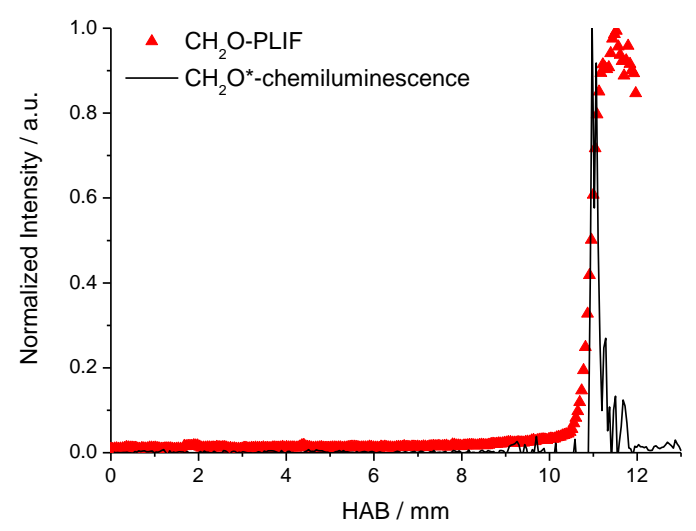

Figure 4. Extracted $\mathrm{CH}_{2} \mathrm{O}^{*}$ and $\mathrm{CH}_{2} \mathrm{O}$-PLIF profiles from Fig. $3, \alpha=40 \mathrm{~s}^{-1}, \phi=0.4, \mathrm{x}_{\mathrm{O} 3}=$ $1.6 \%$.

\section{Temperature profiles}

Since one of the purposes of this study is the quantification of the heat release from the cool flame, temperature profiles were measured and compared to simulated profiles obtained with Aramco 1.3 and the current model, as pictured in Figure 5 for two conditions, at a fixed equivalence ratio of 0.3 , strain rates of 40 and $50 \mathrm{~s}^{-1}$, and a respective ozone mole fraction in the mixture of 1.8 and $2.0 \%$. As mentioned in the computational methods section, the temperature profile was not used as input for the simulations, but calculated by solving the energy equation. The $\mathrm{CH}_{2} \mathrm{O}^{*}$ chemiluminescence axial profile has been plotted in order to visualize the exact position of the flame without the perturbation induced by the thermocouple. 

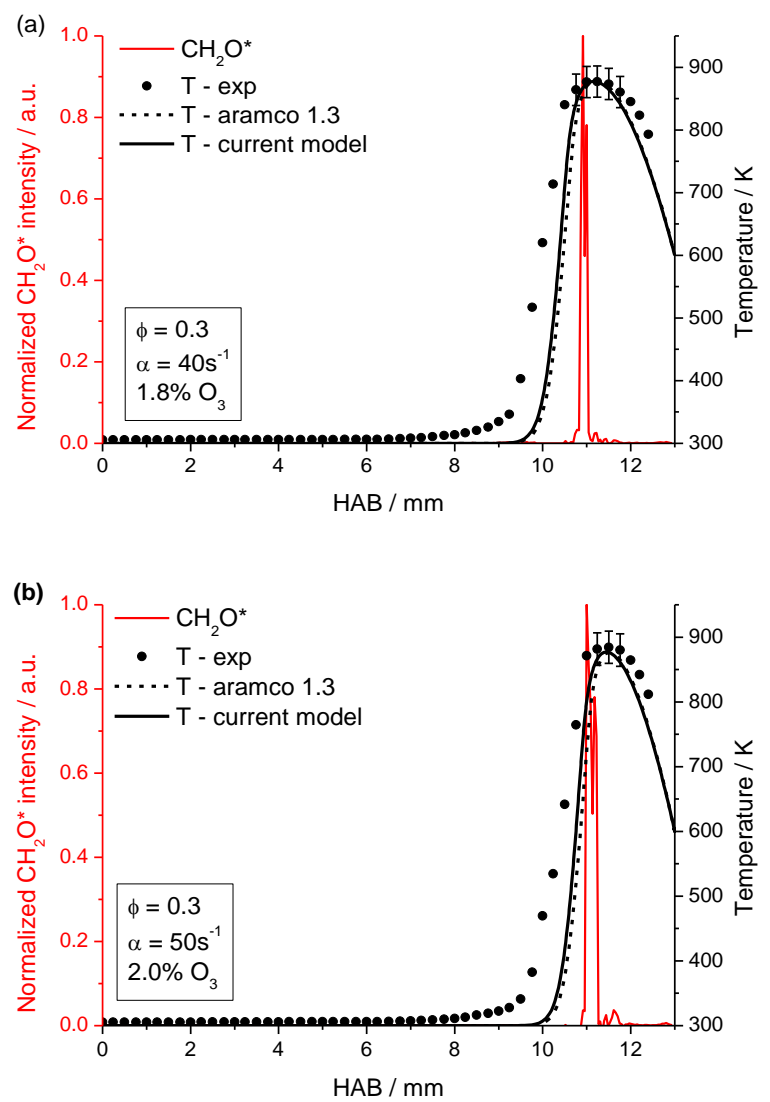

Figure 5. Temperature profiles, (a) $\alpha=40 \mathrm{~s}^{-1}, \phi=0.3,1.8 \% \mathrm{O}_{3}$, (b) $\alpha=50 \mathrm{~s}^{-1}, \phi=0.3,2.0 \% \mathrm{O}_{3}$.

Comparisons between simulated and experimental results show a close agreement on the maximal temperature of the cool flame, which does not exceed $900 \mathrm{~K}$ in both cases, as well as the height above the burner where this maximum is observed. Downstream the flame front, the decrease of the temperature under the plate is captured within the experimental uncertainty in the simulation. No significant change in the temperature profile can be observed between the Aramco 1.3 model and the current model, except that the temperature rise happens at a slightly lower HAB using the current model, which will be discussed in the next section. The largest discrepancy can be observed at the flame front and upstream, where perturbation of the flame by the thermocouple is evidenced by comparing the experimental temperature profile with the chemiluminescence signal. This results in a steeper temperature gradient in the simulation in comparison with the experiments. This phenomenon can be confirmed by increasing the diameter of the thermocouple, leading to a more and more deformed temperature gradient as the diameter increases, without affecting the maximal temperature of the flame, as shown in Fig. S1.

It is expected that in non-isothermal experiments, such as RCM or shock tube configurations, the increase of the temperature induces a loss of competitivity of the low temperature chain branching against propagation or termination reactions. As a consequence, the reactivity decreases, illustrated by the Negative Temperature Coefficient (NTC). In the current configuration, the same cause results in an interruption of the low-temperature reactivity 
downstream from the cool flame, where the temperature reaches a maximum between the flame front and the stagnation plate. In this context, it is of interest to note that the maximum measured temperatures for both flames presented here are very close, $877 \mathrm{~K}$ for the flame $\phi=0.3, \alpha=50 \mathrm{~s}^{-}$ ${ }^{1}$ and $\mathrm{x}_{\mathrm{O} 3}=1.8 \%$ and $884 \mathrm{~K}$ for the flame $\phi=0.3, \alpha=50 \mathrm{~s}^{-1}$ and $\mathrm{x}_{\mathrm{O} 3}=2.0 \%$.

\section{Flame stabilization}

The influence of ozone on the flame front position is presented in Figure 6 for two different strain rates, 40 and $50 \mathrm{~s}^{-1}$, and equivalence ratios varying from 0.2 to 0.5 . A flashback limit is also represented, corresponding to the situation where ozone causes a transition towards a 'hot' flame.
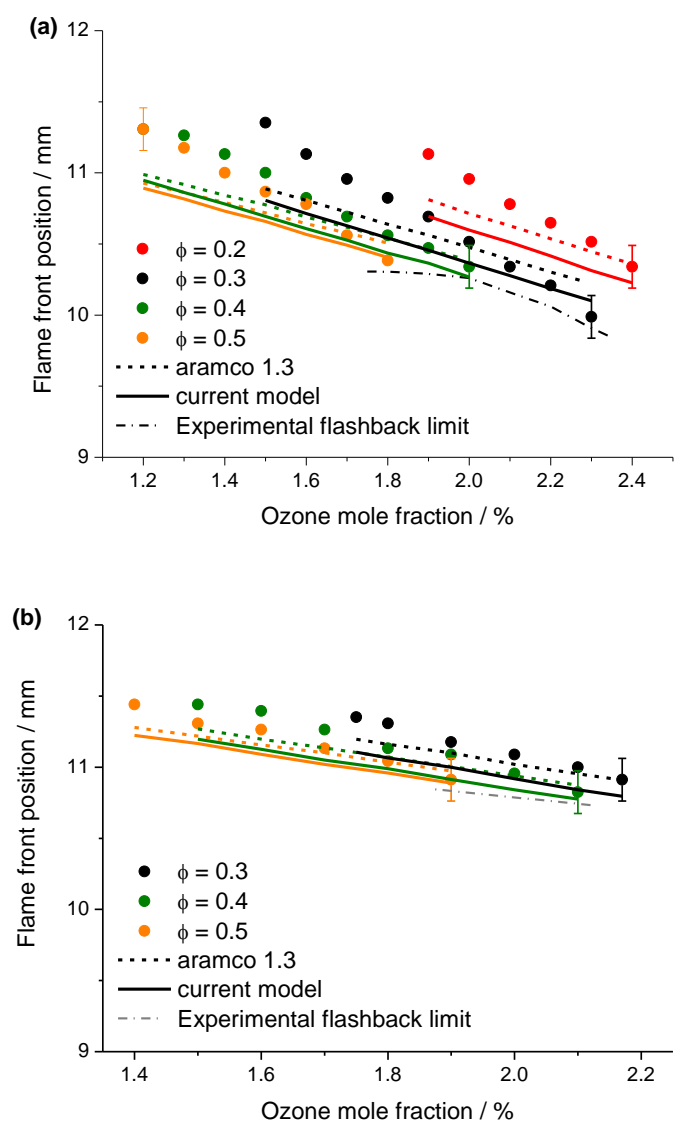

Figure 6. Evolution of the flame front position as a function of the ozone mole fraction. (a) $\alpha=$ $40 \mathrm{~s}^{-1}$ (left), (b) $\alpha=50 \mathrm{~s}^{-1}$ (right).

As the ozone concentration increases, the flame front position decreases in all cases. This behavior is well captured by both models, and the agreement between experimental and simulated flame front positions is overall good, with a maximum discrepancy of about $500 \mu \mathrm{m}$ at the lowest ozone concentrations. As the equivalence ratio decreases, the required ozone mole fraction for flame stabilization and flashback increases, which is also very well predicted in the simulations. The flame front position is however slightly underestimated by the current model, 
which could be attributed to the modification of the rate constants for both isomerization reactions of the $\mathrm{ROO} \cdot$ and $\cdot \mathrm{OOCH}_{2} \mathrm{OCH}_{2} \mathrm{O}_{2} \mathrm{H}$ radicals ${ }^{44}$, causing a rise of reactivity in the low temperature range. This modification was however conserved in the mechanism as it results in improved prediction of both first-stage and total IDT in the low-temperature range, as can be seen in the Supplementary Material (Figures S2-S4) for three different sets of data. Possible solutions to the discrepancy between the predictions of the current model and the experimental flame front positions include improvements in the physical model used in the simulations, as well as the identification of sensitive reactions with regards to the burning velocity of the cool flames.

Figure 7 shows the experimental and simulated effect of the ozone mole fraction on the maximal temperature downstream of the cool flame. As the mole fraction of ozone in the mixture is increased, this temperature increases, demonstrating the influence of ozone on the NTC behavior. This observation is well reproduced in the simulations, and agrees with the results from Foucher et al..$^{34}$ who described a reduction of the NTC intensity, coupled to an increase of the heat release of the cool flame, as the ozone concentration increases. As indicated before, if the $\mathrm{O}_{3}$ concentration in the mixture was increased above the values presented here, it would result in a flashback, as represented with a dashed line in Figure 7. Finally, one can note that at $\phi=0.3, \alpha$ $=40 \mathrm{~s}^{-1}$, the simulated influence of $\mathrm{O}_{3}$ on the flame temperature is less pronounced with the current model than with Aramco 1.3, leading to a divergence of $5 \mathrm{~K}$ at the highest ozone concentration in the mixture, which stays within the uncertainty limit of the experimental flame temperature measurement.

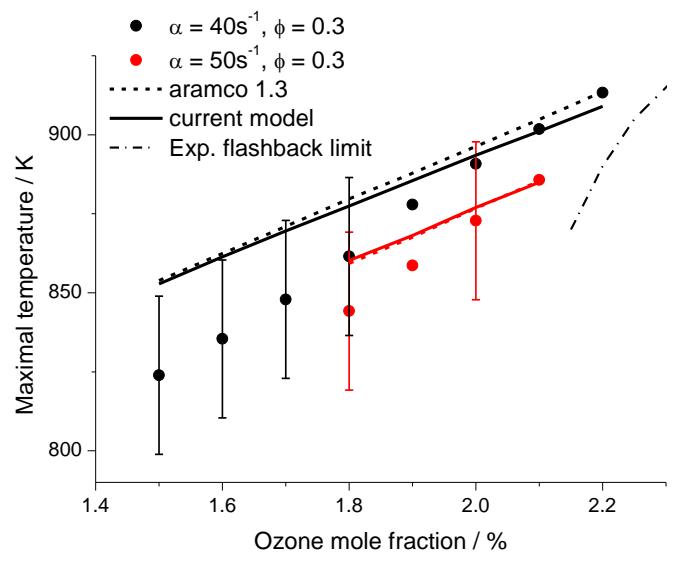

Figure 7. Effect of the ozone mole fraction on the maximal cool flame temperature at $\phi=0.3$ and $\alpha=40 \mathrm{~s}^{-1}$ (black) and $50 \mathrm{~s}^{-1}$ (red). Experiments are represented with symbols, simulations with lines.

Figure 8 presents the effect of the equivalence ratio on the flame front position at two strain rates, 40 and $50 \mathrm{~s}^{-1}$, and for a constant ozone mole fraction of $1.9 \%$ in the mixture. The flame front tends to get closer to the burner as the equivalence ratio increases for both conditions, indicating an increase in the cool flame propagation speed, as demonstrated numerically by Ju et $a l .{ }^{50}$ and Brown et al. ${ }^{51}$ in ultra-lean conditions. This trend, as well as the flame front positions, is 
also captured in the simulations within the uncertainty limit, except at the lowest equivalence ratio of $\phi=0.2$. As shown in the previous section, the different flame fronts simulated with the current model are located at a lower HAB than with the Aramco 1.3 model, the agreement remaining fair.

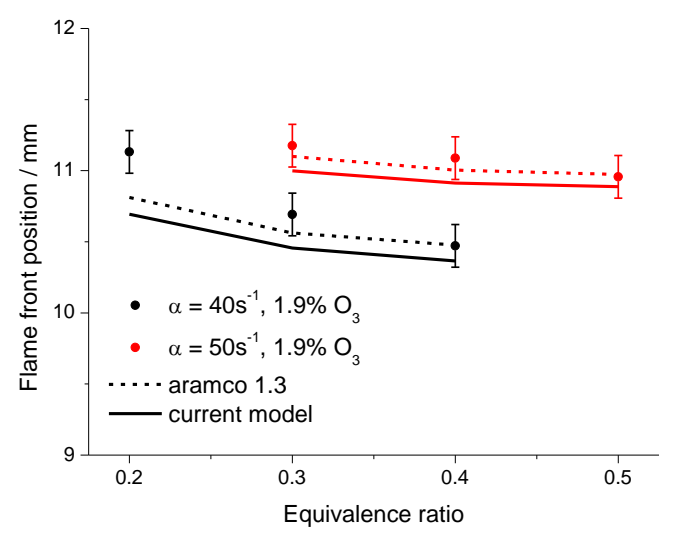

Figure 8. Effect of the equivalence ratio on the flame front position at fixed strain rates $\alpha=40 \mathrm{~s}^{-1}$ (black) and $50 \mathrm{~s}^{-1}$ (red) and ozone mole fraction $\mathrm{x}_{\mathrm{O} 3}=1.9 \%$.

\section{Species mole fraction profiles}

In order to improve the understanding of the mechanisms governing the occurrence and stabilization of cool flames, the mole fraction profiles of the reactants and major stable species formed in the flame were established using the procedure described previously. The comparison between the experimental and simulated results are presented in Figure 9 and Figure 10, for two selected flames with a strain rate $\alpha=50 \mathrm{~s}^{-1}$, at a respective equivalence ratio $\phi=0.3$ and $\phi=0.5$, and ozone mole fraction $\mathrm{x}_{\mathrm{O} 3}=2.0 \%$ and $\mathrm{x}_{\mathrm{O} 3}=1.7 \%$. The corresponding $\mathrm{CH}_{2} \mathrm{O}^{*}$ chemiluminescence profile for each case is also plotted in order to visualize the flame front position. As described in the computational methods section, two different simulation approaches were used, and the results for the simulations with facility effects (simulated with the current model) are also plotted in the figures for the fuel and the $\mathrm{O}_{3}$ case. 

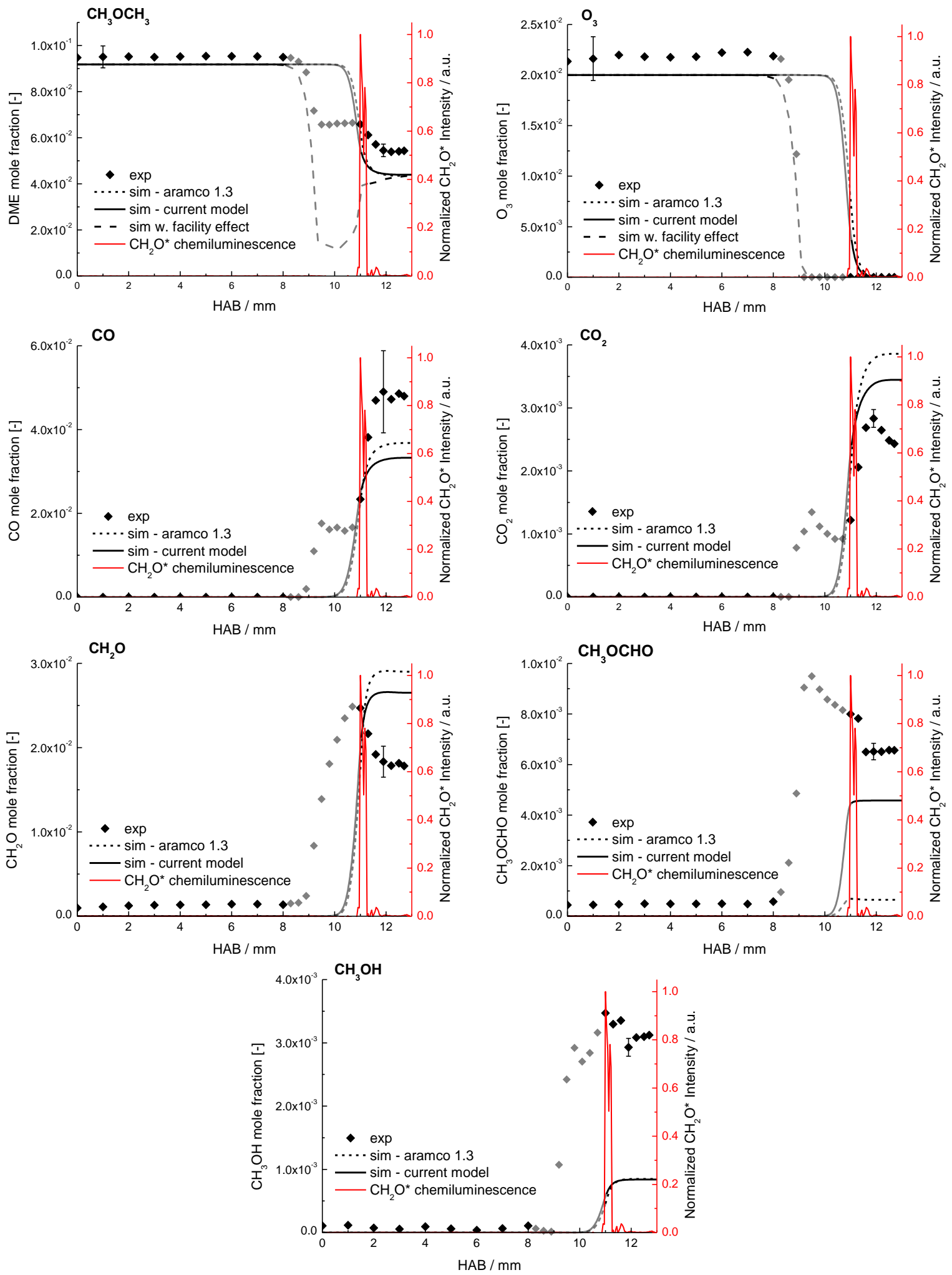

Figure 9. Experimental and simulated species mole fractions profiles, $\phi=0.3, \alpha=50 \mathrm{~s}^{-1}, \mathrm{x}_{\mathrm{O} 3}=$ $2.0 \%$. Grey points represent the perturbated zone where in-capillary reactivity takes place. 

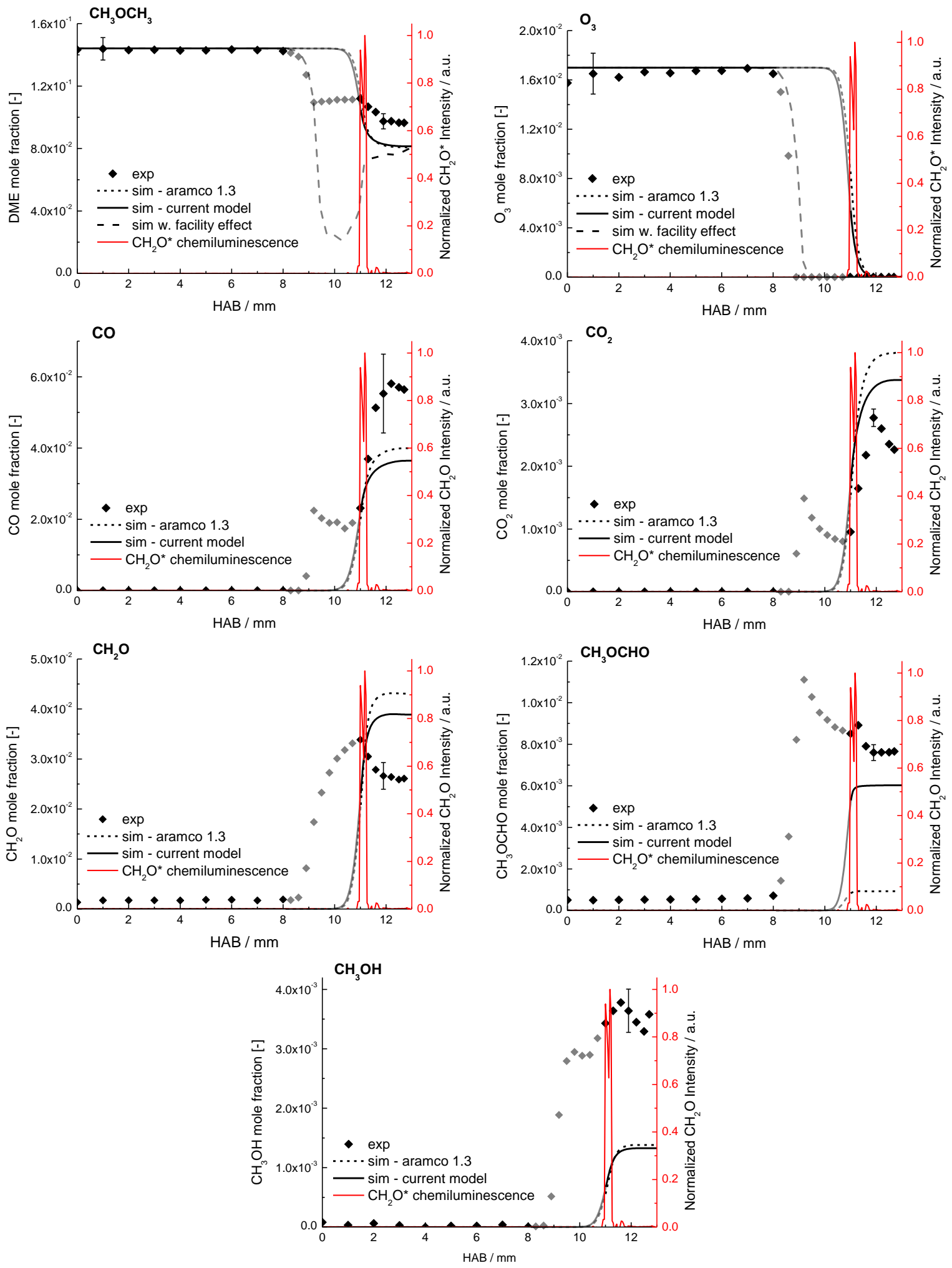

Figure 10. Experimental and simulated species mole fractions profiles, $\phi=0.5, \alpha=50 \mathrm{~s}^{-1}, \mathrm{x}_{03}=$ $1.7 \%$. Grey points represent the perturbated zone where in-capillary reactivity takes place. 
One can first note that the mole fraction profiles of the intermediates show a plateau downstream from the flame front, demonstrating that at this position the reactivity is globally halted and the mixture has reached the negative temperature coefficient domain. The experimental mole fraction profiles demonstrate significant reactivity upstream from the flame front, motivating the "facility effect" modeling procedure described in the computational methods section, which simulates the sampling capillary as a PFR with a fixed temperature profile. The modeling results including facility effects demonstrate the conversion of ozone in the pre-flame region with excellent agreement. However, in the upstream region where reactivity is observed (grey points on graphs), agreement on the other species mole fractions cannot be expected because surface deactivation of ozone is probably an important process inside the capillary $^{52}$, and is not considered in the "facility effect" simulations. This modeling procedure therefore presents a worst-case scenario, where the reactivity inside the capillary is largely overestimated, as can be witnessed on the overestimated conversion of DME by this procedure in the pre-flame region. Considering the reactivity inside the capillary however allows to demonstrate:

- that the reactivity observed upstream from the flame is due to the presence of ozone-rich mixtures inside the capillary, as reported by Hajilou et al. for dimethyl ether ${ }^{24}$ and propane $^{53}$ ozone-assisted cool flames,

- that since both simulation approaches lead to comparable results, i.e. within the experimental uncertainty limits, in the post-flame region, the post-flame mole fractions can be trusted to build useful kinetic analysis.

The discussion will thus focus on the post-flame region, i.e. at $\mathrm{HAB}$ greater than $11 \mathrm{~mm}$, where ozone has been fully converted in the flame. The fuel, $\mathrm{CH}_{3} \mathrm{OCH}_{3}$, is partially consumed through the flame, resulting in a $30-40 \%$ conversion of the fuel into low temperature oxidation products for both flames. Both models slightly over-predict the DME conversion. This partial conversion of the fuel is typical of the cool flame process. Ozone is totally decomposed downstream of the flame front, forming atomic oxygen, $\mathrm{O}$ :, and molecular oxygen. The O: atom will then further react with the fuel molecule, giving $\bullet \mathrm{OH}$ and radicals, yielding $\mathrm{CH}_{3} \mathrm{O} \bullet$ or $\mathrm{CH}_{3} \mathrm{OCH}_{2} \mathrm{O} \cdot$ by addition reactions, and therefore enabling the initiation of the reactivity in our conditions. The fuel radical will then undergo several $\mathrm{O}_{2}$ additions, leading to the formation of products characteristics of its low temperature oxidation.

On the products side, $\mathrm{CH}_{2} \mathrm{O}$ presents a profile showing a decrease of the mole fraction in the post-flame region, which is consistent with the obtained PLIF results, as shown in Figure 11 for the flame at $\phi=0.5$. A deviation exists when comparing the intrusive and non-intrusive method in the pre-flame region, which can be directly related to the perturbation of the flame by the sampling capillary. The important production of formaldehyde is typical of a cool flame, which can be produced from the decomposition of the hydroperoxymethoxymethyl radical, - $\mathrm{CH}_{2} \mathrm{OCH}_{2} \mathrm{OOH}$, formed after oxygen addition on the fuel radical and isomerization. 


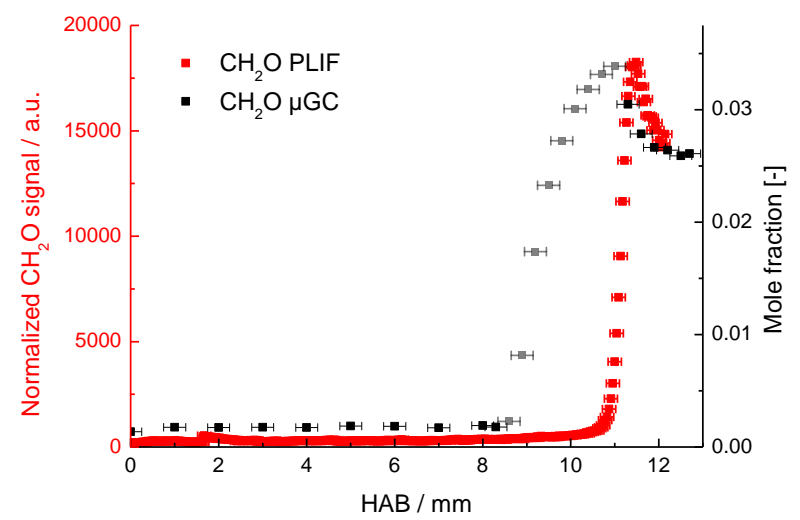

Figure 11. Comparison between $\mathrm{CH}_{2} \mathrm{O}$ profiles obtained by PLIF and $\mu \mathrm{GC}, \phi=0.5, \alpha=50 \mathrm{~s}^{-1}$, $\mathrm{x}_{\mathrm{O} 3}=1.7 \%$. Grey points represent the perturbated zone where in-capillary reactivity takes place.

The modifications made to the model allowed to improve the performance of the model in the prediction of the $\mathrm{CH}_{2} \mathrm{O}$ profile in both flames. $\mathrm{CH}_{2} \mathrm{O}$ can be produced by the fuel radical betascission and the decomposition of $\bullet \mathrm{QOOH}$. The update of the kinetic parameters of formation of -QOOH ${ }^{44}$ by internal $\mathrm{H}$-atom migration have the effect of decreasing the reaction rate constant of this reaction for temperatures higher than $700 \mathrm{~K}$ in comparison to Aramco 1.3. Moreover, the consumption of methoxymethoxyl radical takes place by $\mathrm{C}-\mathrm{C}$ and $\mathrm{C}-\mathrm{H}$ beta-scissions in Aramco 1.3, the first one being favored. However, an experimental and theoretical study of these reactions showed that more than $95 \%$ of the consumption of $\mathrm{CH}_{3} \mathrm{OCH}_{2} \mathrm{O}$ - happens by $\beta-\mathrm{CH}$ bond cleavage ${ }^{43}$. Finally, the addition reaction $\mathrm{CH}_{3} \mathrm{OCH}_{2} \bullet+\mathrm{O}:=\mathrm{CH}_{3} \mathrm{OCH}_{2} \mathrm{O} \bullet$ was added to the $\operatorname{model}^{43}$. The formation of the methoxymethoxy radical will compete with fuel radical addition on $\mathrm{O}_{2}$, explaining the improvement in the prediction of the mole fraction of $\mathrm{CH}_{2} \mathrm{O}$ by the current model.

Using the work of Song. et $a l^{43}$, combined with the utilization of the methyl formate submechanism from Minwegen et al. ${ }^{46}$ led to significant improvement of the prediction of the formation of methyl formate by the current model. This improvement is also observable for the $\mathrm{CO}_{2}$ profile, where the current model shows better performance in comparison with Aramco 1.3. It can be noted that this high $\mathrm{CO} / \mathrm{CO}_{2}$ ratio is typical of the low temperature combustion of the fuel, as the thermal conversion of $\mathrm{CO}$ to $\mathrm{CO}_{2}$ is not effective given the limited maximal temperature of the flame ${ }^{54}$. Finally, methanol was also measured as a minor product of the low temperature combustion of dimethyl ether. Both models underestimate the formation of this species by about a factor 3 in both flames, demonstrating the need for further improvement of the submechanism for this species. One can note that the rate constants used in Aramco 1.3 for the $\mathrm{CH}_{3} \mathrm{OCH}_{3}+\mathrm{CH}_{3} \mathrm{O} \bullet$ reaction, forming $\mathrm{CH}_{3} \mathrm{OCH}_{2} \bullet$ and $\mathrm{CH}_{3} \mathrm{OH}$, are taken by analogy with the $\mathrm{CH}_{3} \mathrm{OH}+\mathrm{CH}_{3} \mathrm{O} \cdot$ reaction ${ }^{55}$, and are unchanged in the current model. This reaction being very sensitive for the production of methanol in our conditions, further investigation of the $\mathrm{CH}_{3} \mathrm{OCH}_{3}$ $+\mathrm{CH}_{3} \mathrm{O} \cdot$ reaction is recommended.

A brute-force sensitivity analysis on the first stage ignition delay was performed using the current model, and is presented on Figure 12. As one can see, the $\mathrm{DME} / \mathrm{O}_{2} / \mathrm{O}_{3}$ system is 
particularly sensitive to the $\mathrm{O}_{3}$ submechanism, containing the three most sensitive reactions (R1, $\mathrm{R} 2$, R3) at $600 \mathrm{~K}$, as its decomposition is crucial in the initiation of combustion in this temperature range. Interestingly, the ROO• isomerization into $\cdot \mathrm{QOOH}(\mathrm{R} 9)$ has a negative effect on the first stage ignition delay at $450 \mathrm{~K}$, but a positive one at $600 \mathrm{~K}$, suggesting that the most important contribution to the reactivity at the lowest temperatures among fuel-specific reactions comes from the $2 \mathrm{CH}_{3} \mathrm{OCH}_{2} \mathrm{OO} \bullet=2 \mathrm{CH}_{3} \mathrm{OCH}_{2} \mathrm{O} \bullet+\mathrm{O}_{2}$ reaction ( $\mathrm{R} 4$ ) as will be highlighted below.

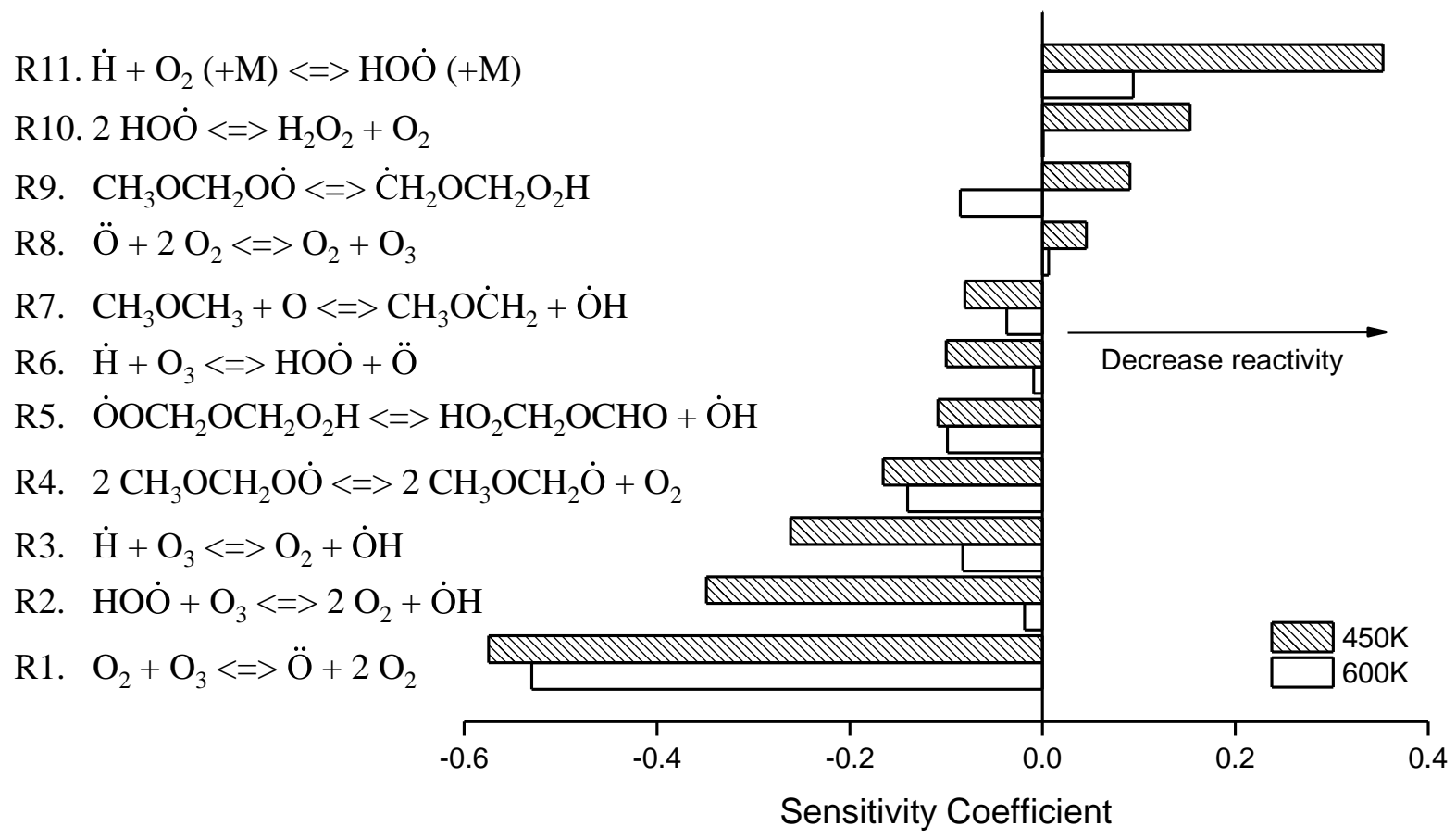

Figure 12. Brute force sensitivity analysis of the first stage ignition delay, modified model. $\phi=$ $0.3, \mathrm{x}_{\mathrm{O} 3}=2.0 \%$.

In parallel a reaction pathway analysis was performed for the $\phi=0.3, \alpha=50 \mathrm{~s}^{-1}, \mathrm{x}_{\mathrm{O} 3}=2.0 \%$ flame case at $5 \%$ and $20 \%$ fuel conversion, corresponding respectively to $\mathrm{HAB}=10.44 \mathrm{~mm}$ and $10.71 \mathrm{~mm}$ and temperatures of $412 \mathrm{~K}$ and $612 \mathrm{~K}$. The main pathways of DME conversion in these conditions are shown in Figure 13. For a comprehensive reading of the figure, the normalized flux is not indicated for values lower than $0.1 \%$. Observed and quantified species in this study are highlighted by black rectangles.

As explained above, the initiation of the reactivity takes place through $\mathrm{H}$-atom abstraction on the fuel molecule, assisted by the decomposition of $\mathrm{O}_{3}$ above the burner, and followed by addition to $\mathrm{O}_{2}$. At $5 \%$ fuel conversion, it is noticed that the most influential reaction of consumption of $\mathrm{ROO}$ - is not the $\mathrm{H}$-atom migration as expected from the low temperature combustion of $\mathrm{DME}^{56}$, but a reaction typical of atmospheric chemistry: Two ROO• radicals forming $2 \mathrm{CH}_{3} \mathrm{OCH}_{2} \mathrm{O}$ - radicals and an $\mathrm{O}_{2}$ molecule. The decomposition of these radicals into methyl formate, $\mathrm{CH}_{3} \mathrm{OCHO}$, plays an important role in the improvement of the prediction of this species by the current model. Bimolecular reactions of peroxy radicals being usually 
representative of atmospheric chemistry, this confirms the recently pointed out link between kinetic studies of low temperature combustion and atmospheric chemistry ${ }^{57}$. A change in the branching ratio is observed when the temperature has increased, at $20 \%$ fuel conversion, where the $\mathrm{ROO} \cdot$ isomerization into $\cdot \mathrm{QOOH}$ becomes more predominant, as commonly observed in LTC studies ${ }^{56}$.

As an overall conclusion on the performance of the modified model, one can observe that it predicts a slightly higher reactivity at low temperature, illustrated by a lower position of the flame in the burner compared to Aramco 1.3, and a lower first stage ignition delay time as shown in the Supplementary Material (Figure S2). However, the changes permitted to better predict the composition of the post-flame area, especially for the methyl formate, which is highly underpredicted by the original model.

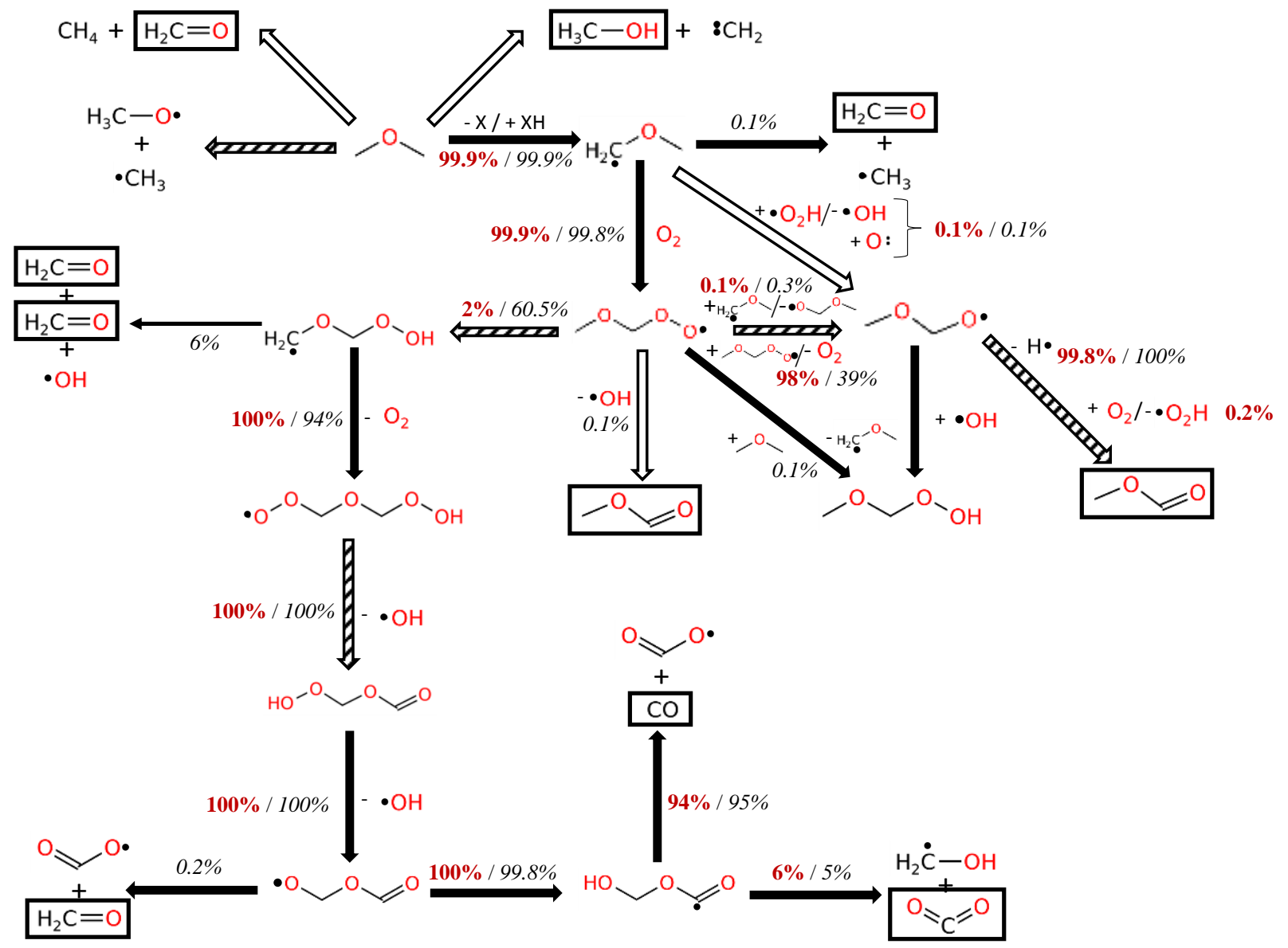

Figure 13. Reaction pathway analysis in the cool flame with the current model at $5 \%, \mathrm{~T}_{\text {flame }}=$ $412 \mathrm{~K}$ (bold, red) and 20\%, $\mathrm{T}_{\text {flame }}=612 \mathrm{~K}$ (italic, black) fuel conversion, $\phi=0.3, \alpha=50 \mathrm{~s}^{-1}, \mathrm{x}_{\mathrm{O} 3}$ $=2.0 \%$. Empty arrows represent added reactions, dashed arrows represent modified reactions in the current model, squared species were experimentally observed and quantified. 


\section{Conclusions}

Stabilized ozone-seeded lean cool flames of dimethyl ether $/ \mathrm{O}_{2}$ were studied in a stagnation plate burner. Two strain rates were fixed, 40 and $50 \mathrm{~s}^{-1}$, the equivalence ratio being varied between 0.2 and 0.5, and the ozone mole fraction being varied between 1.2 and $2.4 \%$ in the mixture. $\mathrm{CH}_{2} \mathrm{O}$-PLIF was used to measure the formaldehyde distribution in the burner, and flame front positions were inferred from the maximum of its derivative in the center of the burner, providing global validation data. Temperature and stables species profiles were measured by coupling thermocouple, gas chromatography, micro-gas chromatography and quadrupole mass spectrometry, thereby allowing detailed validation of kinetic models on the majority of the species formed in such flames. Simulations from the Aramco 1.3 model, coupled to an $\mathrm{O}_{3}$ submechanism, were compared to the experimental data, yielding satisfactory agreement on the global validation targets, and the model was further updated to better reproduce the measured distribution of products in the post-flame region.

Ozone has a strong promoting effect on the low temperature combustion of dimethyl ether, and its mole fraction is directly correlated to the position of the flame in the burner. These results highlight the fact that ozone can not only be considered as a provider of radicals facilitating the initiation of low temperature combustion, but also strongly affects the species distribution. Such initiation of reactivity at very low temperatures strengthens the contribution to radical chainbranching of reactions usually associated to atmospheric chemistry conditions.

The newly developed experimental setup, as well as the associated numerical methods therefore constitute an efficient tool for the kinetic study of cool flames.

\section{SUPPORTING INFORMATION}

Supplementary experimental data and validation of the proposed model on experimental data from the literature are provided in the Supplementary Material.

\section{ACKNOWLEDGMENTS}

This work is a contribution to the LabEx CaPPA project funded by the French National Agency under contract "ANR-11-LABX-0005-01 » and to the CPER research project CLIMIBIO funded by the French Ministère de l'Enseignement Supérieur et de la Recherche. The authors thank the Regional Council "Hauts-de-France » and the "European Regional Development Fund » for their financial support to these projects. The authors would also like to thank the technical staff from PC2A laboratory for the help in the construction of the burner. 


\section{REFERENCES}

(1) Agarwal, A. K. Biofuels (Alcohols and Biodiesel) Applications as Fuels for Internal Combustion Engines. Progress in Energy and Combustion Science 2007, 33 (3), 233-271.

(2) Iannuzzi, S. E. Combustion Behavior and Soot Formation/Oxidation of Oxygenated Fuels in a Cylindrical Constant Volume Chamber. Combustion and Flame 2016, 167, 49-59.

(3) Iannuzzi, S. E.; Barro, C.; Boulouchos, K.; Burger, J. POMDME-Diesel Blends: Evaluation of Performance and Exhaust Emissions in a Single Cylinder Heavy-Duty Diesel Engine. Fuel 2017, 203, 57-67.

(4) Olah, G. A.; Goeppert, A.; Prakash, G. K. S. Chemical Recycling of Carbon Dioxide to Methanol and Dimethyl Ether: From Greenhouse Gas to Renewable, Environmentally Carbon Neutral Fuels and Synthetic Hydrocarbons. J. Org. Chem. 2009, 74 (2), 487-498.

(5) Centi, G.; Quadrelli, E. A.; Perathoner, S. Catalysis for $\mathrm{CO}_{2}$ Conversion: A Key Technology for Rapid Introduction of Renewable Energy in the Value Chain of Chemical Industries. Energy Environ. Sci. 2013, 6 (6), 1711-1731.

(6) Burger, J.; Siegert, M.; Ströfer, E.; Hasse, H. Poly(Oxymethylene) Dimethyl Ethers as Components of Tailored Diesel Fuel: Properties, Synthesis and Purification Concepts. Fuel 2010, 89 (11), 3315-3319.

(7) Schmitz, N.; Burger, J.; Ströfer, E.; Hasse, H. From Methanol to the Oxygenated Diesel Fuel Poly(Oxymethylene) Dimethyl Ether: An Assessment of the Production Costs. Fuel 2016, 185, 67-72.

(8) Musculus, M. P. B.; Miles, P. C.; Pickett, L. M. Conceptual Models for Partially Premixed Low-Temperature Diesel Combustion. Progress in Energy and Combustion Science 2013, 39 (2-3), 246-283.

(9) Zhou, L.; Dong, K.; Hua, J.; Wei, H.; Chen, R.; Han, Y. Effects of Applying EGR with Split Injection Strategy on Combustion Performance and Knock Resistance in a Spark Assisted Compression Ignition (SACI) Engine. Applied Thermal Engineering 2018, 145, 98-109.

(10) Battin-Leclerc, F. Detailed Chemical Kinetic Models for the Low-Temperature Combustion of Hydrocarbons with Application to Gasoline and Diesel Fuel Surrogates. Progress in Energy and Combustion Science 2008, 34 (4), 440-498.

(11) Herbinet, O., Husson, B., Serinyel, S., Cord, M., Warth, V., Fournet, R., Glaude, P.-A., Sirjean, B., Battin-Leclerc, F., Wang, Z. et al., Experimental and Modeling Investigation of the Low-Temperature Oxidation of $n$-Heptane. Combustion and Flame 2012, 159 (12), $3455-3471$.

(12) Vanhove, G.; Yu, Y.; Boumehdi, M. A.; Frottier, O.; Herbinet, O.; Glaude, P.-A.; BattinLeclerc, F. Experimental Study of Tetrahydrofuran Oxidation and Ignition in LowTemperature Conditions. Energy Fuels 2015, 29 (9), 6118-6125.

(13) Song, H.; Dauphin, R.; Vanhove, G. A Kinetic Investigation on the Synergistic LowTemperature Reactivity, Antagonistic RON Blending of High-Octane Fuels: Diisobutylene and Cyclopentane. Combustion and Flame 2020, 220, 23-33. 
(14) Cheng, S.; Saggese, C.; Kang, D.; Goldsborough, S. S.; Wagnon, S. W.; Kukkadapu, G.; Zhang, K.; Mehl, M.; Pitz, W. J. Autoignition and Preliminary Heat Release of Gasoline Surrogates and Their Blends with Ethanol at Engine-Relevant Conditions: Experiments and Comprehensive Kinetic Modeling. Combustion and Flame 2021, 228, 57-77.

(15) Humphry, D. Some New Experiments and Observations on the Combustion of Gaseous Mixtures, with an Account of a Method of Preserving a Continued Light in Mixtures of Inflammable Gases and Air without Flame. The Royal Society 1817, 77-85.

(16) Minetti, R.; Corre, C.; Pauwels, J.-F.; Devolder, P.; Sochet, L.-R. On the Reactivity of Hydroperoxy Radicals and Hydrogen Peroxide in a Two-Stage Butane-Air Flame. Combustion and Flame 1991, 85 (1-2), 263-270.

(17) Carlier, M.; Corre, C.; Minetti, R.; Pauwels, J.-F.; Ribaucour, M.; Sochet, L.-R. Autoignition of Butane: A Burner and a Rapid Compression Machine Study. Symposium (International) on Combustion 1991, 23 (1), 1753-1758.

(18) Ombrello, T.; Won, S. H.; Ju, Y.; Williams, S. Flame Propagation Enhancement by Plasma Excitation of Oxygen. Part I: Effects of $\mathrm{O}_{3}$. Combustion and Flame 2010, 157 (10), 1906-1915.

(19) Reuter, C. B.; Won, S. H.; Ju, Y. Cool Flames Activated by Ozone Addition. In 53rd AIAA Aerospace Sciences Meeting; American Institute of Aeronautics and Astronautics: Kissimmee, Florida, 2015.

(20) Lee, M.; Fan, Y.; Reuter, C. B.; Ju, Y.; Suzuki, Y. DME/Oxygen Wall-Stabilized Premixed Cool Flame. Proceedings of the Combustion Institute 2019, 37 (2), 1749-1756.

(21) Reuter, C. B.; Won, S. H.; Ju, Y. Experimental Study of the Dynamics and Structure of Self-Sustaining Premixed Cool Flames Using a Counterflow Burner. Combustion and Flame 2016, 166, 125-132.

(22) Reuter, C. B.; Zhang, R.; Yehia, O. R.; Rezgui, Y.; Ju, Y. Counterflow Flame Experiments and Chemical Kinetic Modeling of Dimethyl Ether/Methane Mixtures. Combustion and Flame 2018, 196, 1-10.

(23) Reuter, C. B.; Won, S. H.; Ju, Y. Flame Structure and Ignition Limit of Partially Premixed Cool Flames in a Counterflow Burner. Proceedings of the Combustion Institute 2017, 36 (1), 1513-1522.

(24) Hajilou, M.; Ombrello, T.; Won, S. H.; Belmont, E. Experimental and Numerical Characterization of Freely Propagating Ozone-Activated Dimethyl Ether Cool Flames. Combustion and Flame 2017, 176, 326-333.

(25) Zhao, P.; Liang, W.; Deng, S.; Law, C. K. Initiation and Propagation of Laminar Premixed Cool Flames. Fuel 2016, 166, 477-487.

(26) Klein-Douwel, R. J. H.; Luque, J.; Jeffries, J. B.; Smith, G. P.; Crosley, D. R. LaserInduced Fluorescence of Formaldehyde Hot Bands in Flames. Appl. Opt. 2000, 39 (21), 3712-3715. 
(27) Liao, H.; Kang, S.; Hansen, N.; Zhang, F.; Yang, B. Influence of Ozone Addition on the Low-Temperature Oxidation of Dimethyl Ether in a Jet-Stirred Reactor. Combustion and Flame 2020, 214, 277-286.

(28) Zhao, H.; Yang, X.; Ju, Y. Kinetic Studies of Ozone Assisted Low Temperature Oxidation of Dimethyl Ether in a Flow Reactor Using Molecular-Beam Mass Spectrometry. Combustion and Flame 2016, 173, 187-194.

(29) Seignour, N.; Ekoto, I.; Foucher, F.; Moreau, B. Measurements and Modeling of Ozone Enhanced Compression Ignition in a Rapid Compression Machine and OpticallyAccessible Engine. SAE Technical Paper 2019, 2019-01-2254.

(30) Metcalfe, W. K.; Burke, S. M.; Ahmed, S. S.; Curran, H. J. A Hierarchical and Comparative Kinetic Modeling Study of $\mathrm{C}_{1}-\mathrm{C}_{2}$ Hydrocarbon and Oxygenated Fuels. Int. J. Chem. Kinet. 2013, 45 (10), 638-675.

(31) Rolon, J. C. Etude theorique et expérimentale de la flamme de diffusion à contre-courant. PhD Thesis, Ecole Centrale de Paris, 1988.

(32) Cormack, A. M. Representation of a Function by Its Line Integrals, with Some Radiological Applications. Journal of Applied Physics 1963, 34 (9), 2722-2727.

(33) Lamoureux, N.; Desgroux, P.; El Bakali, A.; Pauwels, J. F. Experimental and Numerical Study of the Role of NCN in Prompt-NO Formation in Low-Pressure $\mathrm{CH}_{4}-\mathrm{O}_{2}-\mathrm{N}_{2}$ and $\mathrm{C}_{2} \mathrm{H}_{2}-\mathrm{O}_{2}-\mathrm{N}_{2}$ Flames. Combustion and Flame 2010, 157 (10), 1929-1941.

(34) Foucher, F.; Higelin, P.; Mounaïm-Rousselle, C.; Dagaut, P. Influence of Ozone on the Combustion of N-Heptane in a HCCI Engine. Proceedings of the Combustion Institute 2013, 34 (2), 3005-3012.

(35) LOGEsoft, Available at: Http://Loge.Se/Products/LOGE_Products.Html.

(36) Goodwin, D.; Moffat, H.; Speth, R. Cantera: An Object-Oriented Software Toolkit for Chemical Kinetics, Thermodynamics, and Transport Processes.; 2015.

(37) Harding, L. B.; Klippenstein, S. J.; Georgievskii, Y. Reactions of Oxygen Atoms with Hydrocarbon Radicals: A Priori Kinetic Predictions for the $\mathrm{CH}_{3}+\mathrm{O}, \mathrm{C}_{2} \mathrm{H}_{5}+\mathrm{O}$, and $\mathrm{C}_{2} \mathrm{H}_{3}+\mathrm{O}$ Reactions. Proceedings of the Combustion Institute 2005, 30 (1), 985-993.

(38) Döntgen, M.; Fenard, Y.; Heufer, K. A. Atomic Partial Charges as Descriptors for Barrier Heights. J. Chem. Inf. Model. 2020, 60 (12), 5928-5931.

(39) Yasunaga, K.; Gillespie, F.; Simmie, J. M.; Curran, H. J.; Kuraguchi, Y.; Hoshikawa, H.; Yamane, M.; Hidaka, Y. A Multiple Shock Tube and Chemical Kinetic Modeling Study of Diethyl Ether Pyrolysis and Oxidation. J. Phys. Chem. A 2010, 114 (34), 9098-9109.

(40) Wang, Z.; Zhang, X.; Xing, L.; Zhang, L.; Herrmann, F.; Moshammer, K.; Qi, F.; KohseHöinghaus, K. Experimental and Kinetic Modeling Study of the Low- and IntermediateTemperature Oxidation of Dimethyl Ether. Combustion and Flame 2015, 162 (4), 11131125.

(41) Keiffer, M.; Miscampbell, A. J.; Pilling, M. J. A Global Technique for Analysing Multiple Decay Curves. Application to the $\mathrm{CH}_{3}+\mathrm{O}_{2}$ System. J. Chem. Soc., Faraday Trans. 2 1988, $84(5), 505-514$. 
(42) Vermeire, F. H.; Carstensen, H.-H.; Herbinet, O.; Battin-Leclerc, F.; Marin, G. B.; Van Geem, K. M. Experimental and Modeling Study of the Pyrolysis and Combustion of Dimethoxymethane. Combustion and Flame 2018, 190, 270-283.

(43) Song, X.; Hou, H.; Wang, B. Mechanistic and Kinetic Study of the $\mathrm{O}+\mathrm{CH}_{3} \mathrm{OCH}_{2}$ Reaction and the Unimolecular Decomposition of $\mathrm{CH}_{3} \mathrm{OCH}_{2} \mathrm{O}$. Phys. Chem. Chem. Phys. 2005, 7 (23), 3980-3988.

(44) Konnov, A. A.; Nilsson, E. J. K.; Christensen, M.; Zhou, C.-W. Combustion Chemistry of Methoxymethanol. Part II: Laminar Flames of Methanol+formaldehyde Fuel Mixtures. Combustion and Flame 2021, 111411-111421.

(45) Rosado-Reyes, C. M.; Francisco, J. S.; Szente, J. J.; Maricq, M. M.; Frøsig Østergaard, L. Dimethyl Ether Oxidation at Elevated Temperatures (295-600 K). J. Phys. Chem. A 2005, 109 (48), 10940-10953.

(46) Minwegen, H.; Döntgen, M.; Hemken, C.; Büttgen, R. D.; Leonhard, K.; Heufer, K. A. Experimental and Theoretical Investigations of Methyl Formate Oxidation Including Hot $\beta$-Scission. Proceedings of the Combustion Institute 2019, 37 (1), 307-314.

(47) Lefkowitz, J. K.; Won, S. H.; Fenard, Y.; Ju, Y. Uncertainty Assessment of Species Measurements in Acetone Counterflow Diffusion Flames. Proceedings of the Combustion Institute 2013, 34 (1), 813-820.

(48) Lamoureux, N.; Desgroux, P. In Situ Laser-Induced Fluorescence and Ex Situ Cavity Ring-Down Spectroscopy Applied to NO Measurement in Flames: Microprobe Perturbation and Absolute Quantification. Energy Fuels 2021, acs.energyfuels.0c03806.

(49) Wißdorf, W., Müller, D., Brachthaüser, Y., Langner, M., Derpmann, V., Klopotowski, S., Polaczek, C., Kersten, H., Brockmann, K., Benter, T., Gas Flow Dynamics in Inlet Capillaries: Evidence for Non Laminar Conditions. J. Am. Soc. Mass Spectrom. 2016, 27 (9), 1550-1563.

(50) Ju, Y.; Reuter, C. B.; Won, S. H. Numerical Simulations of Premixed Cool Flames of Dimethyl Ether/Oxygen Mixtures. Combustion and Flame 2015, 162 (10), 3580-3588.

(51) Brown, M. C; Belmont, E. L. Experimental Characterization of Ozone-Enhanced nDecane Cool Flames and Numerical Investigation of Equivalence Ratio Dependence. Combustion and Flame 2021, 230, 111429-111442.

(52) Ouederni, A.; Limvorapituk, Q.; Bes, R.; Mora, J. C. Ozone Decomposition on Glass and Silica. Ozone: Science \& Engineering 1996, 18 (5), 385-416.

(53) Hajilou, M.; Belmont, E. Characterization of Ozone-Enhanced Propane Cool Flames at Sub-Atmospheric Pressures. Combustion and Flame 2018, 196, 416-423.

(54) Vandooren, J.; Peeters, J.; Tiggelen, P. J. V. Rate Constant of the Elementary Reaction of Carbon Monoxide with Hydroxyl Radical. Symposium (International) on Combustion 1975, 15 (1), 745-753.

(55) Tsang, W. Chemical Kinetic Data Base for Combustion Chemistry. Part 2. Methanol. Journal of Physical and Chemical Reference Data 1987, 16 (3), 471-508. 
(56) Burke, U., Somers, K. P., O'Toole, P., Zinner, C. M., Marquet, N., Bourque, G., Petersen, E. L., Metcalfe, W. K., Serinyel, Z., Curran, H. J., An Ignition Delay and Kinetic Modeling Study of Methane, Dimethyl Ether, and Their Mixtures at High Pressures. Combustion and Flame 2015, 162 (2), 315-330.

(57) Benoit, R.; Belhadj, N.; Lailliau, M.; Dagaut, P. On the Similarities and Differences between the Products of Oxidation of Hydrocarbons under Simulated Atmospheric Conditions and Cool Flames. Atmos. Chem. Phys. 2021, 21 (10), 7845-7862.

\section{LIST OF CAPTIONS}

Figure 1. Stagnation plate burner setup used in this study.

Figure 2. Stabilization map. Stability limits are represented by continuous lines at $40 \mathrm{~s}^{-1}$, and dashed lines at $50 \mathrm{~s}^{-1}$.

Figure 3. Raw $\mathrm{CH}_{2} \mathrm{O}^{*}$ chemiluminescence (left) and $\mathrm{CH}_{2} \mathrm{O}-\mathrm{PLIF}$ (right). $\alpha=40 \mathrm{~s}^{-1}, \phi=0.4, \mathrm{x}_{\mathrm{O} 3}$ $=1.6 \%$. The dashed lines represent the burner (bottom) and plate (top) positions, the solid line represents the top of the laser sheet. The color bar on the right indicates the relative intensity of each image, between 0 and 1 .

Figure 4. Extracted $\mathrm{CH}_{2} \mathrm{O}^{*}$ and $\mathrm{CH}_{2} \mathrm{O}$-PLIF profiles from Fig. $3, \alpha=40 \mathrm{~s}^{-1}, \phi=0.4, \mathrm{x}_{\mathrm{O} 3}=1.6 \%$.

Figure 5. Temperature profiles, (a) $\alpha=40 \mathrm{~s}^{-1}, \Phi=0.3,1.8 \% \mathrm{O}_{3}$, (b) $\alpha=50 \mathrm{~s}^{-1}, \Phi=0.3,2.0 \% \mathrm{O}_{3}$.

Figure 6. Evolution of the flame front position as a function of the ozone mole fraction. (a) $\alpha=$ $40 \mathrm{~s}^{-1}$ (left), (b) $\alpha=50 \mathrm{~s}^{-1}$ (right).

Figure 7. Effect of the ozone mole fraction on the maximal cool flame temperature at $\phi=0.3$ and $\alpha=40 \mathrm{~s}^{-1}$ (black) and $50 \mathrm{~s}^{-1}$ (red). Experiments are represented with symbols, simulations with lines.

Figure 8. Effect of the equivalence ratio on the flame front position at fixed strain rates $\alpha=40 \mathrm{~s}^{-1}$ (black) and $50 \mathrm{~s}^{-1}$ (red) and ozone mole fraction $\mathrm{x}_{\mathrm{O} 3}=1.9 \%$.

Figure 9. Experimental and simulated species mole fractions profiles, $\phi=0.3, \alpha=50 \mathrm{~s}^{-1}, \mathrm{x}_{03}=$ $2.0 \%$.

Figure 10. Experimental and simulated species mole fractions profiles, $\phi=0.5, \alpha=50 \mathrm{~s}^{-1}, \mathrm{x}_{03}=$ $1.7 \%$. Grey points represent the perturbated zone where in-capillary reactivity takes place.

Figure 11. Comparison between $\mathrm{CH}_{2} \mathrm{O}$ profiles obtained by PLIF and $\mu \mathrm{GC}, \phi=0.5, \alpha=50 \mathrm{~s}^{-1}$, $\mathrm{x}_{\mathrm{O} 3}=1.7 \%$. Grey points represent the perturbated zone where in-capillary reactivity takes place. 
Figure 12. Brute force sensitivity analysis of the first stage ignition delay, modified model. $\phi=$ $0.3, \mathrm{x}_{\mathrm{O} 3}=2.0 \%$.

Figure 13. Reaction pathway analysis in the cool flame with the current model at $5 \%, \mathrm{~T}_{\text {flame }}=$ $412 \mathrm{~K}$ (bold, red) and $20 \%, \mathrm{~T}_{\text {flame }}=612 \mathrm{~K}$ (italic, black) fuel conversion, $\phi=0.3, \alpha=50 \mathrm{~s}^{-1}, \mathrm{x}_{\mathrm{O} 3}$ $=2.0 \%$. Empty arrows represent added reactions, dashed arrows represent modified reactions in the current model, squared species were experimentally observed and quantified.

Table 1. Modifications operated on the Aramco $1.3\left(+\mathrm{O}_{3}\right.$ submechanism) model.

TOC Graphic

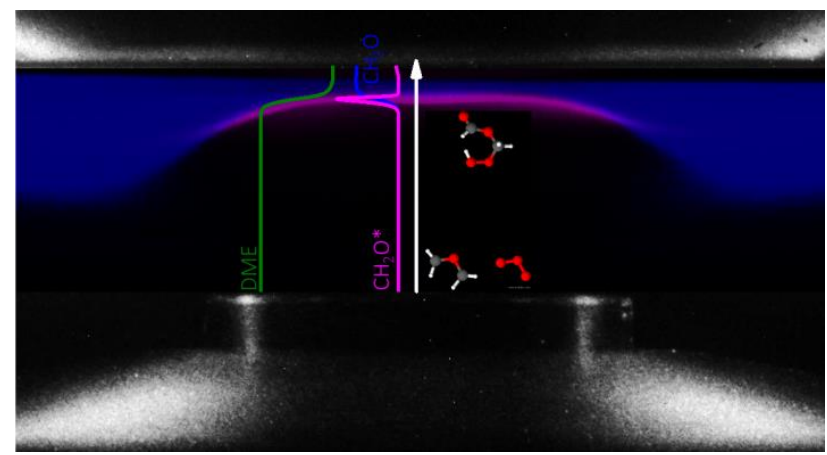

